\title{
Wright's late works
}

Evolution and the Genetics of Populations. Vol. 4: Variability within and among Natural Populations. By Sewall Wright. (University of Chicago: Chicago and London, 1978.) \$46.90; £26.25.

VERDI wrote Otello when he was 73 and completed Falstaff at the age of 80 , though twenty years earlier he had produced some minor works like Trovatore and Rigoletto. Sewall Wright, though he had contributed extensively to the scientific literature since 1915, published his first book, the first volume in this series of four, in 1968 at the age of 78 and the final two have now appeared in quick succession. The first laid the biometrical and genetic foundations and the second, almost entirely theoretical, extended these to the population level in terms of gene frequencies and concluded with a section on quantitative genetics. The third volume was to discuss the evidence but while the first two were being written so much new evidence became available that it has now become two-the first dealing primarily with evidence from laboratory experimentation and the present one with that from natural populations. The new information came mostly from two new techniques. The first of these, starch gel electrophoresis, has not only produced a great deal of information for the study of population structures (as can be seen from the present contents of journals like Evolution) but also answered a previously unanswerable question: What proportion of loci are segregating in wild populations? (the answer is, however, restricted to those loci specifying peptide chains). The second kind of information, from amino acid sequences, can provide a direct genetic measure of the rate of evolutionary substitution at such loci.

Wright's general approach in these final volumes is to analyse specific papers in some detail (sometimes with a re-analysis of his own). For instance, he deals with some work from the early days of genetics like that of Castle on hooded rats (Wright was a junior author of the paper in 1916) and Sumner's work on Peromyscus, but also discusses repetitive sequences in DNA and treats extensively the evidence from biochemical polymorphisms in American Drosophila populations from Ayala and his colleagues. The volumes form a valuable reference work and provide a source of critical discussion.

Wright is the last of the three exponents of mathematical studies of evolution made up of himself, Fisher and Haldane, and the final chapters give his summing up of the present situation. The three, working almost independently over about forty years, were very different in temperament and in training. Fisher and Haldane had degrees in mathematics from Cambridge and $\mathrm{Oxford}$, respectively; Wright had a degree in Zoology from a small mid-Western college and continued his experimental work with guinea pigs until he retired from Chicago. Nevertheless, he has always shown extraordinary mathematical insight in solving the problems that he encountered. In fact, a paper of his in 1915 may be considered as foreshadowing the invention of analysis of variance.

He has, I think, always felt that his ideas suffered from a simplistic representation by Fisher and his colleagues. I remember him saying once that "The position got complicated by the appearance of another person in the argument, with the same name as myself but holding completely different views". He felt himself saddled with a naive outlook about the importance of sudden reductions in population size leading to "genetic drift". He was a little surprised to have some British authors scorn "classical random drift" while espousing the "founder principle" which he thought of as a special case of the former. "While it is useful to make such distinctions, it is evident that most of those who have done so have failed to grasp the general principle of effective size in relation to random drift". When Mayr made his criticism of "bean bag genetics" at Cold Spring Harbor in 1959, Haldane felt it necessary to write in deply; Wright did not, he had always taken a more sophisticated view. He returns to the differences in approach on page 464 of the final volume. "It is sometimes supposed, following Mayr (1959), that the early mathematical studies of evolution under Mendelian heredity by Haldane, Fisher and myself were all essentially equivalent, being based on the same simplified biological premises: populations almost homallelic with respect to an array of
Alan Robertson

'wildtype' genes except for rare favourable mutations, fixed one at a time, by mass selection, the model referred to by Mayr as 'bean bag' evolution. Actually the processes on which we put major emphasis [Haldane on the basis of major mutations; Fisher on the basis of multiple, largely minor mutations; Wright on the basis of local peak-shifts among interaction systems] were about as different as possible, under the common assumption of Mendelian heredity. Each, however, might be valid for particular characters under particular conditions in species with particular population structures".

His view of the importance of periods of small local population size was not so much that this could of itself lead to fixation in a species but rather that, in an interacting system, such chance changes in gene frequency could allow the population to move, as a consequence of the subsequent selection, from one adaptive peak to another. As with all models involving interactions between many loci, it is not amenable to direct algebraic treatment and Wright's approach has been mainly verbal, dealing numerically with specific examples.

In the past decade the old arguments took on new life in the 'neutralistselectionist' controversy about the mechanisms of the maintenance of genetic variation within populations (the evidence coming mostly from electrophoresis), and about the rate of gene substitution in protein evolution. Ironically, the neutralist view corresponded somewhat with the more simplistic versions of his views which he had rejected so indignantly in the 1930s. From his discussion on both these points, it is clear that he is in essence a 'selectionist', though he is writing before the recent findings that modifications of electrophoretic technique could increase greatly, at least for some loci in Drosophila, the number of alleles known to be segregating in populations.

The fascination of these final volumes comes from the breadth of historical perspective: for the greater part of the development of modern genetics, Wright was really there.

Alan Robertson is a Professor in the Department of Genetics at the University of Edinburgh, UK. 